\title{
Near-infrared spectroscopy (NIRS) neurofeedback as a treatment for children with attention deficit hyperactivity disorder (ADHD)-a pilot study
}

\author{
Anna-Maria Marx ${ }^{1}$, Ann-Christine Ehlis ${ }^{2}$, Adrian Furdea ${ }^{1}$, Martin Holtmann ${ }^{3}$, Tobias Banaschewski ${ }^{4}$, \\ Daniel Brandeis ${ }^{4,5}$, Aribert Rothenberger ${ }^{6}$, Holger Gevensleben ${ }^{6}$, Christine M. Freitag ${ }^{7}$, \\ Yvonne Fuchsenberger ${ }^{7}$, Andreas J. Fallgatter ${ }^{2}$ and Ute Strehl ${ }^{1 *}$ \\ ${ }^{1}$ Institute for Medical Psychology and Behavioral Neurobiology, University of Tuebingen, Tuebingen, Germany \\ ${ }^{2}$ Department of Psychiatry and Psychotherapy, Psychophysiology and Optical Imaging, University of Tuebingen, Tuebingen, Germany \\ ${ }^{3}$ LWL-University Hospital for Child and Adolescent Psychiatry, Ruhr-University Bochum, Hamm, Germany \\ ${ }^{4}$ Department of Child and Adolescent Psychiatry and Psychotherapy, Central Institute of Mental Health, Medical Faculty Mannheim of the University of Heidelberg, \\ Mannheim, Germany \\ ${ }^{5}$ Department of Child and Adolescent Psychiatry, University of Zuerich, Zuerich, Switzerland \\ ${ }^{6}$ Clinic for Child and Adolescent Psychiatry, University Medical Center of Goettingen, Goettingen, Germany \\ Department of Child and Adolescent Psychiatry, Psychosomatics and Psychotherapy, Goethe-University Frankfurt am Main, Frankfurt am Main, Germany
}

\section{Edited by:}

Martijn Arns, Research Institute

Brainclinics, Netherlands

Reviewed by:

Lars Kuchinke, Ruhr Universität

Bochum, Germany

Martin J. Herrmann, Universtity of

Würzburg, Germany

*Correspondence:

Anna-Maria Marx and Ute Strehl Institute for Medical Psychology and Behavioral Neurobiology, University of Tuebingen, Silcherstr. 5, Tuebingen 72076, Germany e-mail: anna-maria.marx@ uni-tuebingen.de;

ute.streh@@uni-tuebingen.de
In this pilot study near-infrared spectroscopy (NIRS) neurofeedback was investigated as a new method for the treatment of Attention Deficit-/Hyperactivity Disorder (ADHD). Oxygenated hemoglobin in the prefrontal cortex of children with ADHD was measured and fed back. 12 sessions of NIRS-neurofeedback were compared to the intermediate outcome after 12 sessions of EEG-neurofeedback (slow cortical potentials, SCP) and 12 sessions of EMG-feedback (muscular activity of left and right musculus supraspinatus). The task was either to increase or decrease hemodynamic activity in the prefrontal cortex (NIRS), to produce positive or negative shifts of SCP (EEG) or to increase or decrease muscular activity (EMG). In each group nine children with ADHD, aged 7-10 years, took part. Changes in parents' ratings of ADHD symptoms were assessed before and after the 12 sessions and compared within and between groups. For the NIRS-group additional teachers' ratings of ADHD symptoms, parents' and teachers' ratings of associated behavioral symptoms, childrens' self reports on quality of life and a computer based attention task were conducted before, 4 weeks and 6 months after training. As primary outcome, ADHD symptoms decreased significantly 4 weeks and 6 months after the NIRS training, according to parents' ratings. In teachers' ratings of ADHD symptoms there was a significant reduction 4 weeks after the training. The performance in the computer based attention test improved significantly. Within-group comparisons after 12 sessions of NIRS-, EEG- and EMG-training revealed a significant reduction in ADHD symptoms in the NIRS-group and a trend for EEG- and EMG-groups. No significant differences for symptom reduction were found between the groups. Despite the limitations of small groups and the comparison of a completed with two uncompleted interventions, the results of this pilot study are promising. NIRS-neurofeedback could be a time-effective treatment for $A D H D$ and an interesting new option to consider in the treatment of $\mathrm{ADHD}$

Keywords: near-infrared spectroscopy (NIRS), fNIRS, neurofeedback, attention deficit hyperactivity disorder (ADHD), children, prefrontal cortex (PFC)

\section{INTRODUCTION}

Attention Deficit-/Hyperactivity Disorder (ADHD) is characterized by the main symptoms of inattention, hyperactivity and impulsivity, leading to deficits in social and/or academic functioning.

In the model of prefrontal lobe executive functions according to Barkley (1997), a deficit in behavioral inhibition in ADHD leads to deficits in executive functions, such as working memory, and in consequence to a deficient self control. Increasing behavioral inhibition should in consequence lead to an increased self control and symptom reduction. Deficits in executive functioning can be observed in children with ADHD compared to healthy controls (Martinussen et al., 2005; Willcutt et al., 2005). On a neurophysiological level, central nervous hypo-arousal during 
working memory tasks measured with fMRI was found in children with ADHD compared to healthy controls (Dickstein et al., 2006; Paloyelis et al., 2007), as well as alterations in the prefrontal cortex (Brennan and Arnsten, 2008) (see also NIRS studies below).

Neurofeedback as a treatment for ADHD can be interpreted as a way to increase behavioral inhibition. Neurofeedback is commonly EEG-feedback of frequency bands or slow cortical potentials (SCP), measuring and feeding back electrical brain activity (Arns et al., 2013; Holtmann et al., 2014b). The training protocols are based on findings of hypoarousal in the resting state EEG (Barry et al., 2003a) or findings on divergent eventrelated potentials (Barry et al., 2003b). EEG-neurofeedback has been proven to be an effective treatment for ADHD as regards to the reduction of inattention, impulsivity and hyperactivity (Arns et al., 2009).

An alternative method to assess brain activity is functional near-infrared spectroscopy (NIRS), measuring hemodynamic correlates of neural activity. Light in the near-infrared spectrum is absorbed to different amounts by oxygenated and deoxygenated hemoglobin allowing to determine relative concentration changes on the cortical surface (Fallgatter and Strik, 1997; Obrig et al., 2000; for an overview on applications see: Ehlis et al., 2014). Higher brain activity is thereby reflected by concentration increases (decreases) of oxygenated (deoxygenated) hemoglobin.

In most of the few NIRS studies comparing children with ADHD to healthy controls in different executive functioning tasks, altered prefrontal activity was observed: some reported reduced activity in ADHD (Negoro et al., 2010; Inoue et al., 2012; Xiao et al., 2012), some reported increased activity in ADHD (Weber et al., 2005; Jourdan Moser et al., 2009). While a few studies suggest a more pronounced involvement of the right lateral prefrontal cortex (Xiao et al., 2012; Yasumura et al., 2014), most report no specific lateralization or even clear bilateral deficits (e.g., Ehlis et al., 2008; Negoro et al., 2010; Inoue et al., 2012). Based on these findings, neurofeedback of hemodynamic activity in the prefrontal cortex could lead to a more effective use of cognitive resources, similar to EEG-neurofeedback.

fMRI-neurofeedback of hemodynamic activity has been investigated in healthy adults, showing the possibility of acquiring selfregulation rapidly in only three to four sessions (Weiskopf et al., 2003, 2004; Caria et al., 2007, 2010). The same was observed for NIRS-neurofeedback in healthy adults (Ayaz et al., 2009). In comparison to EEG-neurofeedback requiring around 30 sessions to gain sufficient self-control, NIRS-neurofeedback could be an interesting alternative, possibly allowing changes in symptomatology in fewer sessions of feedback.

Based on these findings we wanted to investigate NIRSneurofeedback as a new method of neurofeedback for children with ADHD, aimed at gaining control over prefrontal hemodynamics. Based on the above mentioned findings in PMRI- and NIRS-studies, the left and right dorsolateral prefrontal cortex was chosen as region of interest for the neurofeedback signal, representing also a key region of executive functioning. Concentration changes in oxygenated hemoglobin were used as feedback signal due to several (partly interrelated) reasons: First, oxygenated hemoglobin was found to show the strongest correlation with the fMRI BOLD signal, probably because of its superior signal-tonoise ratio as compared to deoxygenated hemoglobin (Strangman et al., 2002). Second, depending on the vascular characteristics of the brain tissue covered by the NIRS optodes, the signal course of deoxygenated hemoglobin can show considerable differences, with cortical activation leading to (the usually expected) decreases, increases or even no changes in $\mathrm{HHb}$ concentration. Oxygenated hemoglobin, on the other hand, consistently shows concentration increases during active task periods (Yamamoto and Kato, 2002) allowing for a more reliable interpretation of oxy$\mathrm{Hb}$ data. Third, previous findings also suggest that the amplitude of change is always larger for oxygenated than for deoxygenated hemoglobin (Yamamoto and Kato, 2002), which is a critical point in feedback trainings that rely on single-trial NIRS data (as in our case).

Besides the general aim to investigate the feasibility of NIRSneurofeedback especially for children with ADHD, the study was designed to assess as primary outcome if NIRS-neurofeedback leads to a reduction of ADHD in parents' ratings and if changes persist 6 months after the training. Additionally, decreased teachers' ratings of ADHD symptoms, decreased parents' and teachers' ratings of associated behavioral symptoms, improvements in children's self-rated quality of life and in the performance in a computer based attention task were expected. As an active control condition neurofeedback of SCPs was selected, as a semi-active control condition feedback of muscular activity of the left and right musculus supraspinatus was chosen (for an overview of control conditions in neurofeedback see Arns et al., 2013). We expected comparable changes in symptomatology compared to EEG-neurofeedback and greater changes in comparison to EMG-feedback after 12 sessions of training.

Additionally, the hemodynamic brain activity was measured during the NIRS-neurofeedback training sessions and a working memory task with parallel NIRS measurement was conducted to measure changes in prefrontal brain activity before and after the training. The hemodynamic data are not part of this paper and will be published separately.

The study was approved by the Ethics Committee of the Medical Faculty of the University of Tuebingen and conducted according to the ethical guidelines and principles of the international Declaration of Helsinki. The multicentre study (ISRCTN76187185) was approved by all local Ethics Committees according to the Declaration of Helsinki. Written informed consent was obtained from parents and children.

\section{MATERIALS AND METHODS PARTICIPANTS}

Inclusion criteria were age between 7;0 and 10;11 years and a full-scale intelligence quotient over 80 (percentile $>9$, assessed with the Colored Progressive Matrices CPM, Raven et al., 1998; German version: Bulheller and Häcker, 2006) and a pre-diagnosis of ADHD by a child psychiatrist, pediatrician or clinical psychologist. Exclusion criteria were an intelligence level under 80 (percentile $\leq 9$ ), medical or neurological disorders, psychiatric 


\begin{tabular}{|c|c|c|c|c|c|}
\hline & & $\begin{array}{c}\text { NIRS-group } \\
\quad n=9\end{array}$ & $\begin{array}{c}\text { EEG-group } \\
\quad n=9\end{array}$ & $\begin{array}{c}\text { EMG-group } \\
n=9\end{array}$ & Kruskal-Wallis \\
\hline Age & $\begin{array}{l}\text { Mdn } \\
\text { IQR }\end{array}$ & $\begin{array}{l}8.92 \\
7.67-10.25\end{array}$ & $\begin{array}{l}9.17 \\
8.00-9.83\end{array}$ & $\begin{array}{l}8.83 \\
8.25-9.50\end{array}$ & $\begin{aligned} H(2) & =0.28 \\
p & =0.869\end{aligned}$ \\
\hline CPM & Mdn & 76.00 & 69.00 & 85.00 & $H(2)=1.94$ \\
\hline Percentile & $I Q R$ & $61.50-97.50$ & $32.00-90.00$ & $72.50-93.50$ & $p=0.380$ \\
\hline EFB-K total & Mdn & 2.77 & 3.00 & 3.20 & $H(2)=0.78$ \\
\hline Raw score & $I Q R$ & $35.00-66.00$ & $26.00-56.50$ & $24.50-52.50$ & $p=0.220$ \\
\hline
\end{tabular}

$M d n=$ median, $I Q R=$ interquartile range,$C P M=$ Colored Progressive Matrices, EFB- $K=$ Parenting scale, $C B C L=$ Child Behavior Checklist

disorders other than oppositional defiant disorder and current participation in a psychotherapeutic treatment.

27 children with ADHD combined type (age $M=8.90$ years, $s d=1.02 ; 9$ female) participated in the study. The diagnosis was confirmed with the supplement for ADHD (German version: Delmo et al., 2000) of the semi-structured interview Kiddie-Sads-Present and Lifetime Version (Kaufman et al., 1997; Kaufman and Schweder, 2003), using DSM-IV criteria.

Nine children ( 3 female) with a mean age of $M=9.00$ years $(s d=1.26)$ took part in the NIRS-feedback. For the EEGand the EMG-group, 18 children were matched to the NIRS-group for gender, medication status and age (EEGgroup: $M=8.85$ years, $s d=0.99,3$ female; EMG-group: $M=8.83$ years, $s d=0.88,3$ female). The children of these two groups were participants in a multicenter neurofeedback study (ISRCTN76187185, Holtmann et al., 2014a) with a total of 144 participants recruited with identical inclusion and exclusion criteria.

As additional screening instruments, all parents rated the child's behavior on the Child behavior checklist (CBCL, Achenbach, 1991; German version: Arbeitsgruppe Deutsche Child Behavior Checklist, 1998) and their own parenting behavior on the Parenting Scale (Arnold et al., 1993; German short version EFB-K: Miller, 2001). Medication status was assessed; seven children in each group with a medication of methylphenidate stopped medication at least $48 \mathrm{~h}$ before the pretest, the post test 2 and the follow-up test. There were no other medication agents (amphetamine, atomoxetine) prescribed in the NIRS-sample, so the matching included only children with a medication of methylphenidate. The groups did not differ significantly in age, IQ percentile, total score of parenting behavior and total score of child's behavior (see Table 1).

\section{PROCEDURE AND MEASUREMENT INSTRUMENTS}

The nine children in the NIRS-group were recruited in the same manner as the children of the two other groups through local advertisements and through pediatricians and child psychiatrists. For the matching of EEG- and EMG-group, 80 complete datasets were used and only gender, medication status, age and IQ were transferred. After matching, the complete dataset was provided. Main matching criteria were same gender and same medication status, followed by nearest age and nearest IQ. The NIRS-group received 12 sessions, the EEG- and EMG-group received 25 sessions of training. For the inter-group comparison, the FBB-ADHS was used after 12 sessions (see Table 2). As there are no NIRSneurofeedback studies investigating children with ADHD so far, the amount of 12 sessions for the NIRS-group was based on the findings in fMRI- and NIRS-neurofeedback with healthy subjects using three to four sessions (see Introduction) and was adapted for practical reasons to the intermediate outcome of the multicentric study, to allow group comparison. The outcome of the full 12 session NIRS-training was thus compared to the intermediate 12 session outcome of the longer EEG- and EMG-training, in order to test for a more rapid clinical improvement with NIRSneurofeedback.

For the pre-post comparison of the NIRS-group ADHD symptoms rated by parents and teachers in the Rating Scale for Attention Deficit Hyperactivity Disorder (Fremdbeurteilungsbogen für Aufmerksamkeitsdefizit-/Hyperaktivitätsstörung, FBBADHS) were assessed as main dependent variables. The parent-rated FBB-ADHS was the primary outcome. The FBBADHS is part of the Diagnostic System for Mental Disorders in Childhood and Adolescence (DISYPS-II, Döpfner et al., 2008). The FBB-ADHS covers the diagnostic criteria for the combined

Table 2 | Measurement points and instruments for within- and between-group comparisons.

\begin{tabular}{lccc}
\hline \multirow{2}{*}{ Measurement point } & \multicolumn{3}{c}{ Measurement instruments } \\
\cline { 2 - 4 } & Parents & Teachers & Children \\
\hline Pretest & FBB-ADHS & FBB-ADHS & KID-KINDL \\
& SDO & SDQ & TAP 2.2 Go/NoGo \\
& & & and Flexibility \\
Post Test 1 & FBB-ADHS & & \\
(after session 12) & & & \\
Post Test 2 & FBB-ADHS & FBB-ADHS & KID-KINDL \\
(4 weeks after & SDO & SDO & TAP 2.2 Go/NoGo \\
session 12) & & & and Flexibility \\
Follow up Test & FBB-ADHS & FBB-ADHS & KID-KINDL \\
(6 months after & SDO & SDO & TAP 2.2 Go/NoGo \\
session 12) & & & and Flexibility \\
\hline
\end{tabular}

Bold marked FBB-ADHS = measurements in all three groups for group comparison. $F B B-A D H S=$ Rating scale for $A D H D, S D Q=$ Strengths and Difficulties Questionnaire, KID-KINDL = Questionnaire for health-related quality of life, TAP 2.2 = Test Battery for Attentional Performance. 


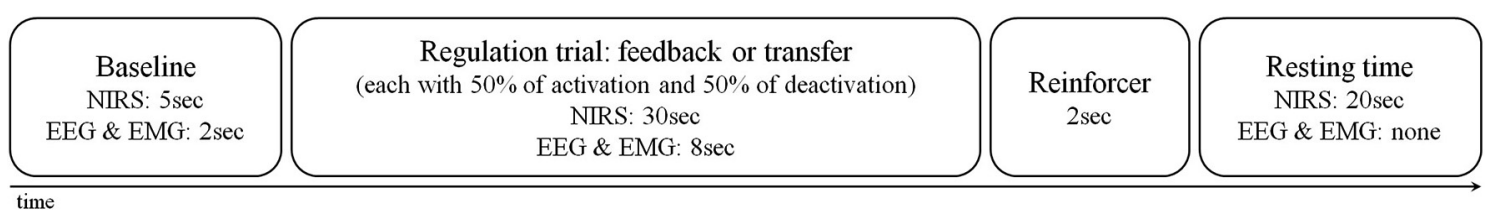

FIGURE 1 | Trial design of NIRS-, EEG- and EMG- blocks. One NIRS session consisted of 2 feedback blocks each with 12 trials and 1 transfer block with 8 trials. An EEG and EMG session consisted of 3 feedback blocks and 1 transfer block each with 40 trials.

type of ADHD according to the Diagnostic and Statistical Manual of the American Psychiatric Association (4th edition; DSM-IV, American Psychiatric Association, 2000) and can be regarded as the German equivalent of the SNAP-IV. Associated behavioral symptoms were assessed with the Strengths and Difficulties Questionnaire (SDQ, Goodman, 1997; German Version: Rothenberger and Woerner, 2004), rated by parents and teachers. Children rated their quality of life in the Kindl-Questionnaire for healthrelated quality of life (KID-KINDL, Ravens-Sieberer, 2003) and childrens' attention and impulsivity were measured with two subtests (Flexibility, Go/NoGo) of a computer based attention task (Test Battery for Attentional Performance, TAP, Zimmermann and Fimm, 2009). The TAP subtest Go/NoGo measures the ability to inhibit reactions (performance variables: median of reaction times, standard deviation of reaction times, omissions and commissions); the subtest Flexibility measures the ability to change the focus of attention (performance variables: median of reaction times, standard deviation of reaction times, commissions). All instruments were applied before training (pretest), 4 weeks (post test 2) and 6 months (follow-up test) after the training. Table 2 gives an overview of measurement points and instruments.

The childrens' pediatricians or the childrens' psychiatrists were asked to rate severity of psychopathology and improvement after treatment on the Clinical Global Impression Scale (Guy, 1976). This data was not analyzed and will not be reported due to low return rates (pretest $n=6$, post test $n=3$, follow up $n=2$ ).

\section{NIRS-NEUROFEEDBACK}

NIRS-neurofeedback training consisted of twelve sessions within 4-6 weeks, with 2-3 sessions per week. Each session comprised three blocks of NIRS-neurofeedback. After the 12 sessions, children were instructed to practice their strategy for 3 weeks in attention-requiring situations at home or school, to facilitate the transfer to everyday life. In order to motivate the children, the whole training was accompanied by a token system in which the children could gain points and swap them for small toys. Tokens were given for good cooperation during a training session, independent of achievement.

The basic parameters of the three trainings (NIRS, EEG, EMG) were comparable. Each session lasted approximately 1 hour with 32 min effective feedback time. The visual layout of the feedback was identical. Compared to electrical brain and muscular activity, changes in hemodynamic activity are somewhat delayed and need more time to return back to baseline. In consequence, hemodynamic neurofeedback trials were designed with longer regulation and resting times (see Figure 1 for a comparison of the three training protocols).

One session comprised 2 feedback blocks each lasting 12 min and one transfer block lasting $8 \mathrm{~min}$. A feedback block consisted of 12 regulation trials. One trial consisted of $20 \mathrm{~s}$ resting time, $5 \mathrm{~s}$ baseline measurement and $30 \mathrm{~s}$ regulation time (see Figure 1 for trial design). The task was to increase or decrease the hemodynamic activity in the prefrontal cortex (in 50\% of cases activation, in $50 \%$ deactivation, in a random order). As feedback the children saw an object on a screen (e.g., a fish), moving from left to right and depicting concentration changes in oxygenated hemoglobin. An arrow in the middle of the screen indicated if activation (pointing upwards) or deactivation (pointing downwards) was expected. In activation trials the concentration of oxygenated hemoglobin should increase in comparison to the baseline, in deactivation trials it should decrease. At the end of a successful trial (= the object was flying at least $7 \mathrm{~s}$ of the last $15 \mathrm{~s}$ regulation time in the expected direction) a sun was shown on the screen as a visual reinforcer. A transfer block consisted of 8 regulation trials in which the moving feedback object was not shown, but the sun at the end of the trial indicated whether the participant was successful. The transfer blocks were included in order to facilitate the transfer to everyday life.

The neurofeedback signal reflected relative concentration changes of oxygenated hemoglobin in the prefrontal cortex. A 52channel NIRS system (Hitachi Optical Topography System ETG4000) was placed over frontal and temporal areas and linked to a neurofeedback device (NeuroConn THERA-PRAX). For the measurement 46 optodes (44 NIRS channels) were used, arranged on two $3 \times 5$ probesets. The probesets were oriented along positions of the 10-20-system of electrode placement. The lowest row of both probesets was oriented frontally with Fpz as midpoint, while the second optode from occipital in the lowest row on each side was lying on T3 respectively T4 (see Figure 2 for channel positions). The neurofeedback signal, that is the signal that controls the "flying" object on the computer's screen, was based on mean concentration changes in oxygenated hemoglobin measured over the right and left dorsolateral prefrontal cortex and computed using the following procedure: In a first step, for each sample in time, the average of the signals from four NIRS channels located over the left and right dorsolateral prefrontal cortex (see Figure 2, blue marking) was computed. This was followed by subtracting the average of the particular probeset ( 22 channels) per side (common average reference). In a last step, the resulting two signals (one corresponding to each side) were averaged and used to provide feedback. This method was adopted to minimize 


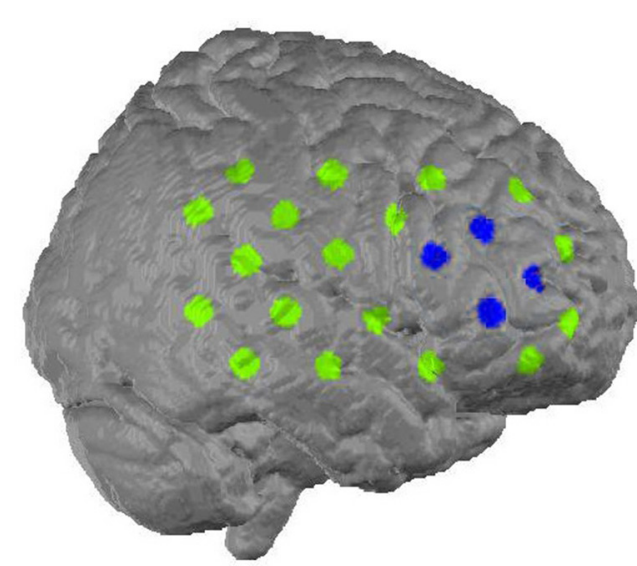

FIGURE 2 | Alignment of the $\mathbf{4 4}$ NIRS channels on the cortex surface (Marx, 2014). The eight channels from which the feedback signal was computed are marked with blue (figure buildt with MATLAB based on

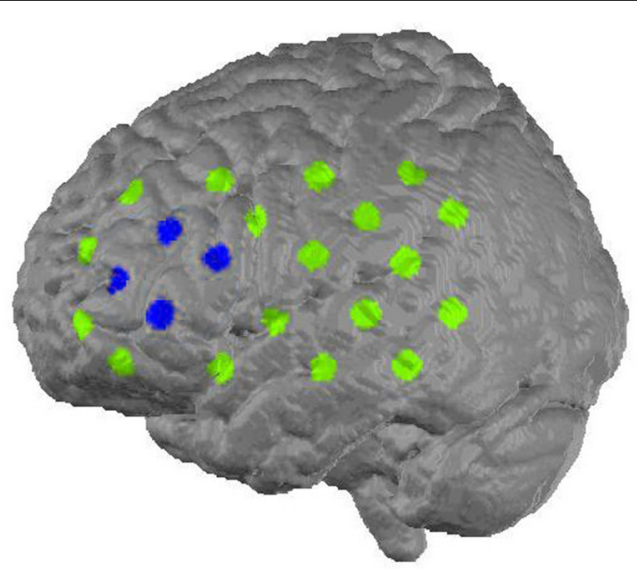

MNI coordinates, available: http://www.jichi.ac.jp/brainlab/virtual_ registration/Result3x5_E.html, Tzourio-Mazoyer et al., 2002; Tsuzuki et al., 2007) the effect of hemodynamic artifacts induced by breathing, head movements or skin blood flow.

The NIRS signals were transmitted to a personal computer via $\mathrm{TCP} / \mathrm{IP}$ protocol for further processing. The feedback signal was computed online using a self-programmed MATLAB routine and it served as input signal for the neurofeedback device.

\section{EEG-NEUROFEEDBACK AND EMG-FEEDBACK}

The EEG- and EMG-group participated in 25 sessions, with a 3 week practice break including an intermediate outcome assessment using the FBB-ADHS after 12 sessions. One session consisted of 3 feedback blocks (with the same visualization as in the NIRS-group) and one transfer block (without feedback object) each lasting $8 \mathrm{~min}$. The blocks consisted of 40 regulation trials. One regulation trial comprised $2 \mathrm{~s}$ baseline measurement and $8 \mathrm{~s}$ regulation time $(50 \%$ of cases activation, $50 \%$ deactivation, in a random order, see Figure 1 for trial design, a detailed description is provided in Holtmann et al., 2014a).

The feedback was conducted with the NeuroConn NEUROPRAX (identical software to THERA-PRAX, possibility to measure more EEG channels). Nine $\mathrm{Ag} / \mathrm{AgCl}$ ring electrodes were used, one at $\mathrm{Cz}$, two at the right and left mastoid (A1 and A2), two central over and under the left eye, two at the left and right corner of both eyes and two at the right and left musculus supraspinatus above the shoulders.

In the EEG-group the EEG-signal (slow cortical potentials at $\mathrm{Cz}$ referenced against $\mathrm{A} 1$, online corrected for eye movements, ground electrode at A2) was fed back, in the EMG-group the EMG-signal was fed back. The task in the EEG-group was to produce a positive or negative shift of the SCPs in comparison to the baseline. The task in the EMG-group was to increase muscle tension on the left side while decreasing it on the right side and vice versa in comparison to the baseline. At the end of a successful trial (= the object was flying at least $2 \mathrm{~s}$ of the last $4 \mathrm{~s}$ regulation time in the expected direction) a sun was shown on the screen as a visual reinforcer.

\section{DATA ANALYSIS AND STATISTICS}

For the FBB-ADHS, the SDQ and the KID-KINDL total scores were calculated according to the test instructions. A higher score in the FBB-ADHS implies more severe ADHD symptoms and a higher score in the SDQ implies a higher occurrence of associated behavioral symptoms, including hyperactivity. A higher score in the KID-KINDL implies a higher self-rated quality of life. For the two TAP subtests, medians of reaction times, standard deviations of reaction times and the numbers of commissions and omissions (only Go/NoGo) were assessed and analyzed. Higher medians of reaction times represent slower reactions; higher standard deviations of reaction times represent a higher variability of reaction times.

IBM SPSS Version 20 was used for statistical analysis. Due to small sample-size, non-parametric tests were applied. Significance level was set to $\alpha \leq 0.05$. Friedman's ANOVAS were conducted for comparisons within the NIRS-group (pretest, post test 2, follow-up test) for the dependent variables. For post hoc analysis Wilcoxon signed-rank tests were conducted. Additionally, effect sizes were calculated $\left(r=\frac{z}{\sqrt{N}}\right)$.

For the comparison of the three groups the initial values of parents' and teachers' ratings of the FBB-ADHD and the SDQ, the child-rated KID-KINDL and the performance data of the TAP subtests were compared with Kruskal-WallisTests and post hoc Mann-Whitney $U$ Tests, to ensure the general comparability of the three groups. To assess the prepost effects of the twelve training sessions for each group separately, three Wilcoxon signed rank tests were conducted for the total scores of the FBB-ADHS comparing pretest and post test 1 within each group. Additionally, differences of the scores were calculated for each group (total score at post test 1 minus total score at pretest, a higher difference implies a higher symptom reduction), and these differences were compared between groups in a Kruskal-WallisTest. 
Table 3 | Medians and interquartile ranges for the dependent variables of the NIRS-group at all measurement points with test statistics.

\begin{tabular}{|c|c|c|c|c|c|}
\hline & & Pretest & Post test 2 & Follow-up test & Friedman's ANOVAS \\
\hline \multirow{2}{*}{$\begin{array}{l}\text { FBB-ADHS total } \\
\text { score parents }\end{array}$} & $M d n$ & 1.65 & 1.05 & 1.05 & $\chi^{2}(2)=6.59$ \\
\hline & $1 Q R$ & $1.33-2.15$ & $0.68-1.33$ & $0.88-1.25$ & $p=0.037$ \\
\hline \multirow{2}{*}{$\begin{array}{l}\text { FBB- ADHS total } \\
\text { score teachers }\end{array}$} & $M d n$ & $1.10(n=7)$ & $1.00(n=8)$ & $1.03(n=8)$ & $\chi^{2}(2)=6.33$ \\
\hline & $I Q R$ & $0.80-2.15$ & $0.44-2.05$ & $0.66-1.51$ & $p=0.042$ \\
\hline \multirow{2}{*}{$\begin{array}{l}\text { KID-KINDL total } \\
\text { score }\end{array}$} & $M d n$ & 4.13 & 4.46 & 4.17 & $\chi^{2}(2)=2.00$ \\
\hline & $1 Q R$ & $3.75-4.46$ & $3.40-4.71$ & $3.98-4.40$ & $p=0.368$ \\
\hline \multirow{2}{*}{$\begin{array}{l}\text { SDQ total score } \\
\text { parents }\end{array}$} & $M d n$ & 18.00 & 16.00 & 14.00 & $\chi^{2}(2)=5.88$ \\
\hline & $I Q R$ & $16.50-23.00$ & $11.50-19.50$ & $9.50-17.50$ & $p=0.053$ \\
\hline \multirow{2}{*}{$\begin{array}{l}\text { SDO total score } \\
\text { teachers }\end{array}$} & $M d n$ & $13.00(n=7)$ & $10.00(n=7)$ & $9.50(n=8)$ & $\chi^{2}(2)=2.78$ \\
\hline & $I Q R$ & $10.00-18.00$ & $6.00-27.00$ & $7.50-23.75$ & $p=0.249$ \\
\hline \multirow{2}{*}{$\begin{array}{l}\text { TAP Go/NoGo median } \\
\text { reaction time }\end{array}$} & $M d n$ & 551.00 & 580.00 & 497.00 & $\chi^{2}(2)=6.91$ \\
\hline & IOR & $450.50-600.00$ & 470-606.50 & $440.00-520.00$ & $p=0.032$ \\
\hline \multirow{2}{*}{$\begin{array}{l}\text { TAP Go/NoGo standard } \\
\text { deviation reaction time }\end{array}$} & $M d n$ & 150.00 & 122.00 & 89.00 & $\chi^{2}(2)=8.97$ \\
\hline & $I Q R$ & $112.50-185.50$ & 87.00-149.50 & $79.00-113.50$ & $p=0.011$ \\
\hline \multirow{2}{*}{$\begin{array}{l}\text { TAP Go/NoGo } \\
\text { commissions }\end{array}$} & $M d n$ & 4.00 & 0.00 & 0.00 & $\chi^{2}(2)=12.96$ \\
\hline & $I O R$ & $1.50-11.50$ & $0.00-2.00$ & $0.00-3.50$ & $p=0.002$ \\
\hline \multirow{2}{*}{$\begin{array}{l}\text { TAP Go/NoGo } \\
\text { omissions }\end{array}$} & $M d n$ & 0.00 & 0.00 & 0.00 & $\chi^{2}(2)=5.38$ \\
\hline & $10 R$ & $0.00-2.00$ & $0.00-0.00$ & $0.00-0.50$ & $p=0.068$ \\
\hline \multirow{2}{*}{$\begin{array}{l}\text { TAP Flexibility median } \\
\text { reaction time }\end{array}$} & $M d n$ & 1276.00 & 929.00 & 1012.00 & $\chi^{2}(2)=6.22$ \\
\hline & $1 Q R$ & $843.00-1468.00$ & $776.50-1092.50$ & 719.50-1144.50 & $p=0.045$ \\
\hline \multirow{2}{*}{$\begin{array}{l}\text { TAP Flexibility standard } \\
\text { deviation reaction time }\end{array}$} & $M d n$ & 534.00 & 350.00 & 320.00 & $\chi^{2}(2)=6.22$ \\
\hline & $1 O R$ & $272.00-630.00$ & $285.00-409.00$ & $227.00-384.50$ & $p=0.045$ \\
\hline \multirow{2}{*}{$\begin{array}{l}\text { TAP Flexibility } \\
\text { commissions }\end{array}$} & $M d n$ & 12.00 & 9.00 & 5.00 & $\chi^{2}(2)=4.22$ \\
\hline & $I O R$ & $6.00-21.00$ & $4.00-17.00$ & $3.50-8.50$ & $p=0.121$ \\
\hline
\end{tabular}

Reaction times in milliseconds, Mdn = Median, $1 Q R=$ interquartile range, bold = significant at $\alpha \leq 0.05, F B B-A D H S=R a t i n g ~ S c a l e ~ f o r ~ A D H D, S D Q=S t r e n g t h s$ and Difficulties Questionnaire, KID-KINDL = Questionnaire for health-related quality of life, TAP = Test Battery for Attentional Performance; if not reported otherwise: $n=9$.

\section{RESULTS}

\section{WITHIN-GROUP COMPARISONS FOR THE NIRS-GROUP}

For an overview of all medians and interquartile ranges for the dependent variables of the NIRS-group at all measurement points with test statistics see Table 3 . Five teacher ratings were not included in the data analysis: one was not sent back (SDQ + FBB-ADHS), one was returned empty (SDQ + FBB-ADHS), three could not be assigned to a measurement point (2 SDQ + FBBADHS, 1 SDQ).

\section{FBB-ADHS}

There are significant differences in the measurement points of the FBB-ADHS total score for the NIRS-group in parents' and teachers' ratings (parents: $\chi^{2}(2)=6.59, p=0.037$; teachers: $\left.\chi^{2}(2)=6.33, p=0.042\right)$. In the post hoc analysis of parents' ratings, $\mathrm{ADHD}$ symptoms significantly decreased from pretest to post test $2(z=-2.49, p=0.013, r=-0.587)$ as well as from pretest to follow-up test $(z=-2.31, p=0.021, r=-0.544)$. There was no significant difference between parents' ratings from post test 2 to follow-up test $(z=-0.51, p=0.611, r=-0.120)$. The post hoc analysis of teachers' ratings revealed a significant decrease of ADHD symptoms in teachers' ratings from pretest to post test 2 $(z=-2.21, p=0.027, r=-0.535)$, but not from pretest to followup test $(z=-1.69, p=0.091, r=-0.410)$ or from post test 2 to follow-up test $(z=-0.34, p=0.735, r=-0.080)$. For medians and interquartile ranges of FBB-ADHS total scores see Figure 3 and Table 3.

\section{SDQ and KID-KINDL}

There were no significant differences in parents' and teachers' ratings of associated behavioral symptoms (SDQ total scores) and in childrens' ratings of quality of life (KID-KINDL) for the three measurement points (parents' ratings SDQ: $\chi^{2}(2)=5.88$, $p=0.053$; teachers' ratings SDQ: $\chi^{2}(2)=2.78, p=0.249$; childrens' ratings KID-KINDL: $\left.\chi^{2}(2)=2.00, p=0.368\right)$. In the post hoc analysis there was a significant decrease in parents' ratings of the SDQ total score from pretest to follow-up test $(z=-2.55, p=0.011, r=-0.602)$. See Figure 4 and Table 3 for medians and interquartile ranges of the SDQ total scores.

\section{TAP}

Go/NoGo. For the subtest Go/NoGo significant differences were found for the three measurement points in standard deviations of reaction times $\left(\chi^{2}(2)=8.97, p=0.011\right)$, commission errors $\left(\chi^{2}(2)=12.96, p=0.002\right)$ and medians of reaction times $\left(\chi^{2}(2)=6.91, p=0.032\right)$. In the post hoc analysis there was a significant difference in the medians of reaction times from post test 2 to follow-up test $(z=-2.52, p=0.012, r=-0.595)$, as shown in Figure 5. The children reacted faster 6 months after the training than 4 weeks after the training. In the post hoc 


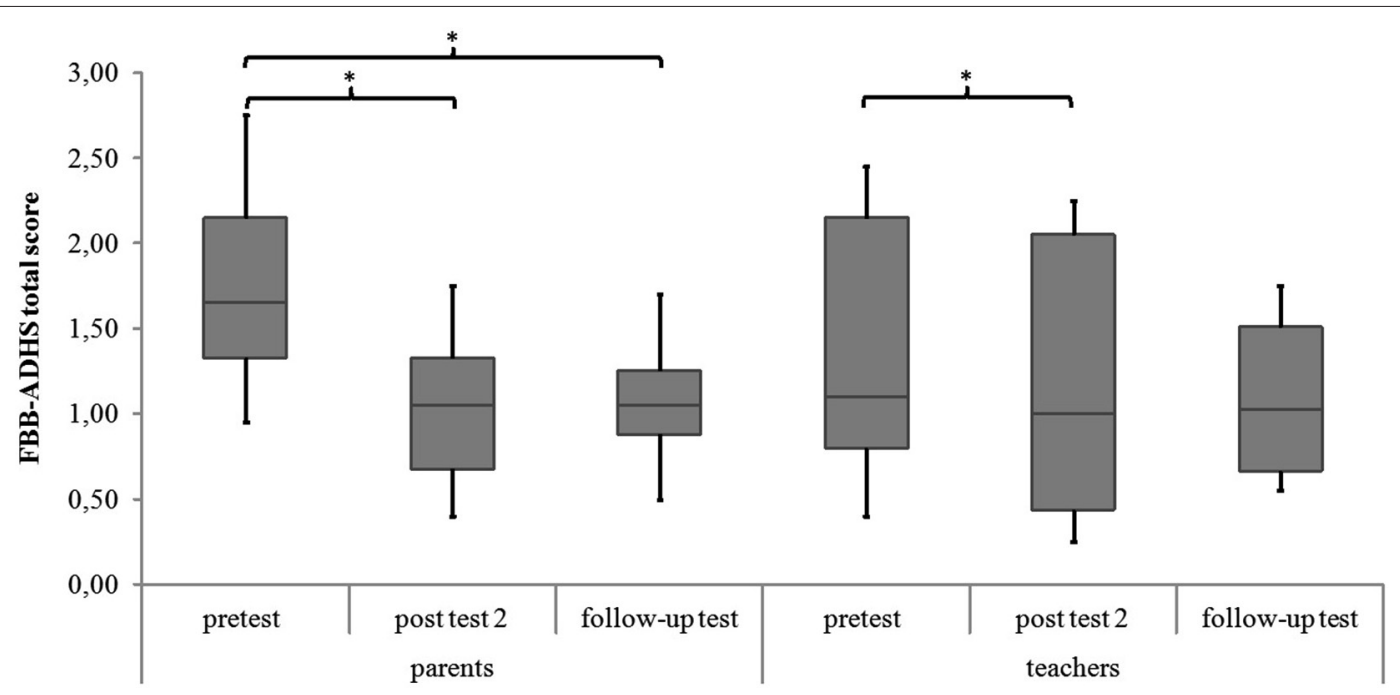

FIGURE 3 | FBB-ADHS total score of parents' and teachers' ratings for all meeasurement points. Middle line of boxes = median, box = interquartile range error bars $=$ minimum respectively maximum, ${ }^{*}=$ significant.

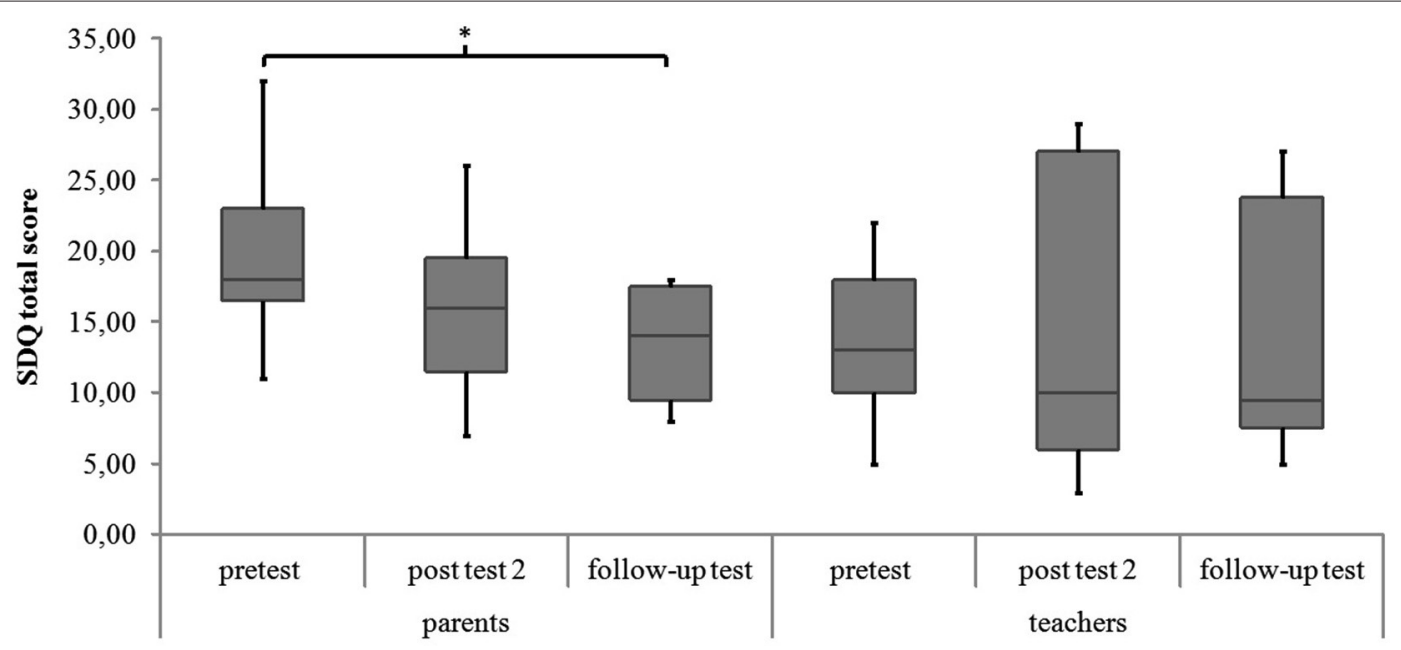

FIGURE 4 | SDQ total score of parents' and teachers' ratings for all measurement points. Middle line of boxes $=$ median, box $=$ interquartile range, error bars $=$ minimum respectively maximum, ${ }^{*}=$ significant.

analyses of the standard deviations of reaction times there was a significant difference between pretest and post test $2(z=-2.38$, $p=0.017, r=-0.561)$ as well as between pretest and follow up test $(z=-2.55, p=0.011, r=-0.600$, see Figure 6). The children reacted with less variability 4 weeks and 6 months after the training in comparison to prior to the training. There were significant differences in commission errors from pretest to post test $2(z=-2.53, p=0.012, r=-0.596)$ and from pretest to follow-up test $(z=-2.37, p=0.018, r=-0.559)$, as shown in Figure 7. The children made fewer commission errors after the training.

Flexibility. In the subtest Flexibility there were significant differences for the medians of reaction times $\left(\chi^{2}(2)=6.22, p=0.045\right)$ and the standard deviations of reaction times $\left(\chi^{2}(2)=6.22\right.$, $p=0.045)$. In the post hoc analysis there were no significant differences for the medians of reaction times (see Figure 5). In the post hoc analysis of the standard deviations of reaction times there was a significant decrease of variability from pretest to post test 2 $(z=-2.31, p=0.021, r=-0.544)$ and from pretest to follow-up test $(z=-2.31, p=0.021, r=-0.544)$, see Figure 6 . There was also a significant decrease of commission errors from pretest to follow-up test $(z=-1.96, p=0.050, r=-0.462)$, see Figure 7 .

\section{WITHIN AND BETWEEN GROUP COMPARISONS FOR EEG-, EMG- AND NIRS-GROUP}

There were no significant differences between groups in the pretest values of parents' and teachers' rating of the ADHD 


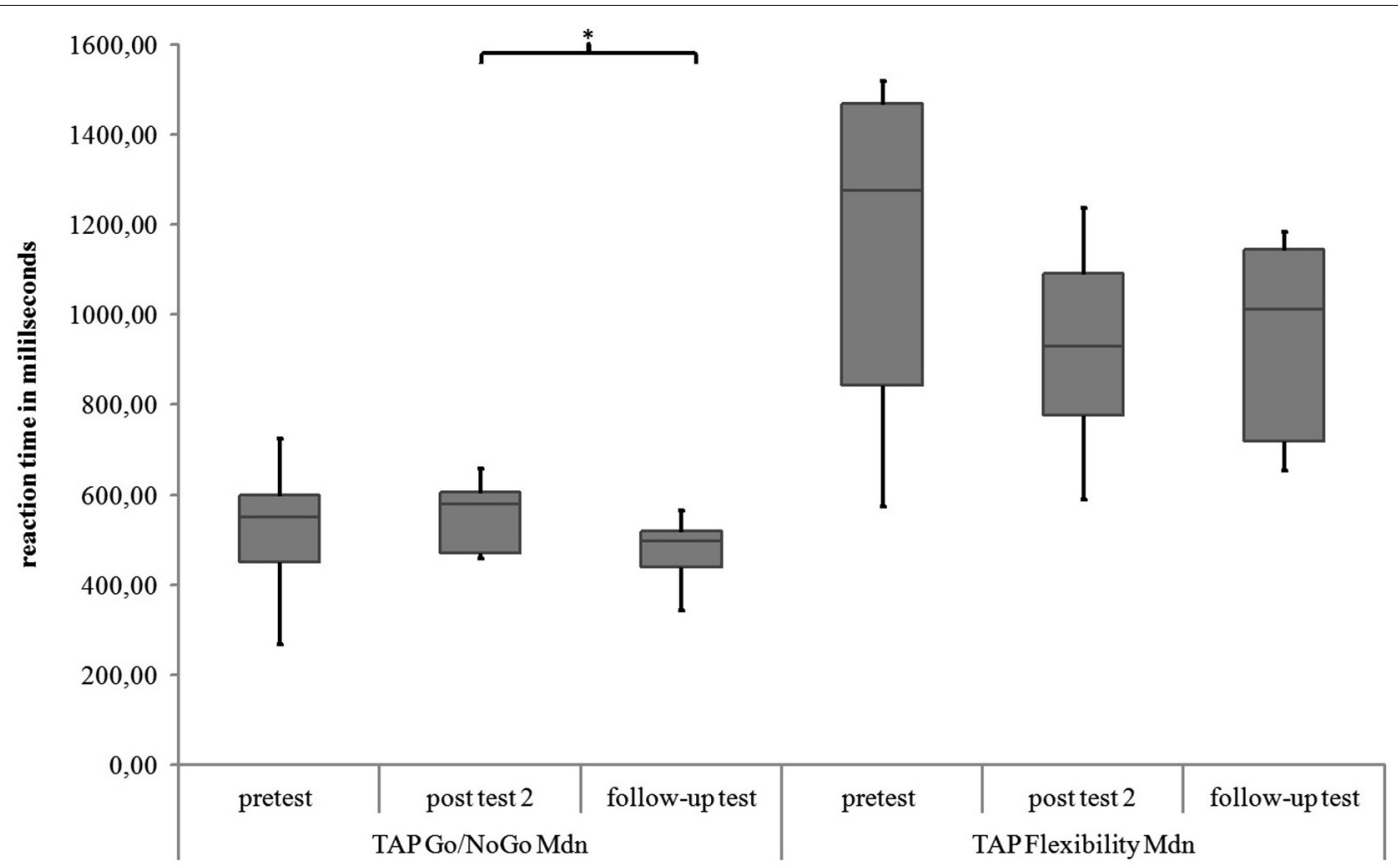

FIGURE 5 | Medians of reaction times for the TAP subtests Go/NoGo and Flexibility for all measurement points. Middle line of boxes = median, box $=$ interquartile range, error bars = minimum respectively maximum, ${ }^{*}=$ significant.

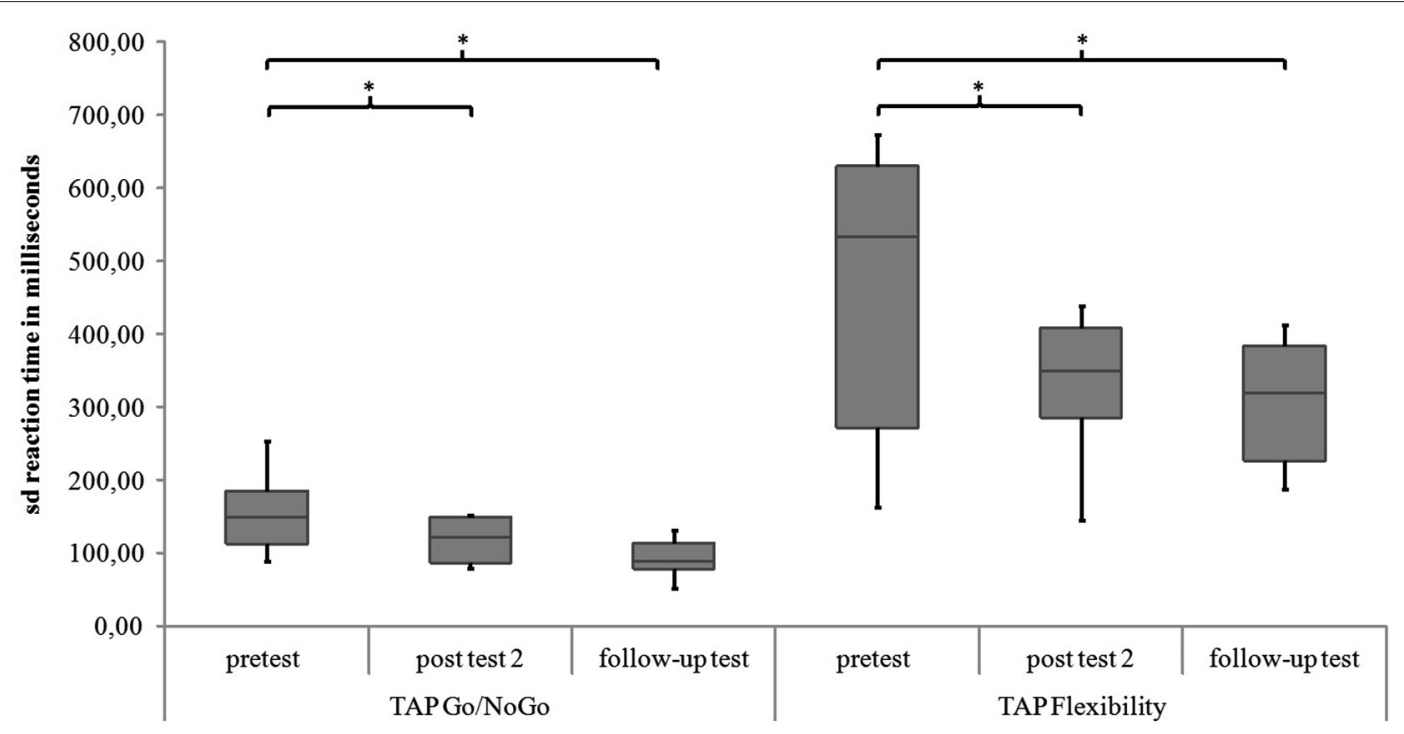

FIGURE 6 | Standard deviations of reaction times for the TAP subtests Go/NoGo and Flexibility for all measurement points. Middle line of boxes $=$ median, box $=$ interquartile range, error bars = minimum respectively maximum, ${ }^{*}=$ significant.

symptoms in the FBB-ADHS and in the teachers' rating of associated behavioral symptoms in the SDQ (see Table 4). Childrens' ratings of the quality of life in the KID-KINDL and parents' ratings of associated behavioral symptoms in the SDQ differed significantly between groups (see Table 4). Post hoc analyses for the SDQ revealed a significant higher score in the EMG-group in comparison to the NIRS-group (NIRS vs. EEG: $U=21.50, z=-1.68, p=0.094$; NIRS vs. EMG: $U=15.00, z=-2.26, p=0.024$; EEG vs. EMG: $U=26.50, z=-1.24, p=0.222$ ). Post hoc analyses for the KID-KINDL showed significant higher quality of life scores in the NIRS-group in comparison to the EEG-group $(U=0.00$, $z=-3.58, p=0.000)$ as well as in comparison to the EMGgroup $(U=0.00, z=-3.58, p=0.000)$, there was no difference between EEG- and EMG-group $(U=26.50, z=-1.25$, $p=0.222$ ). 


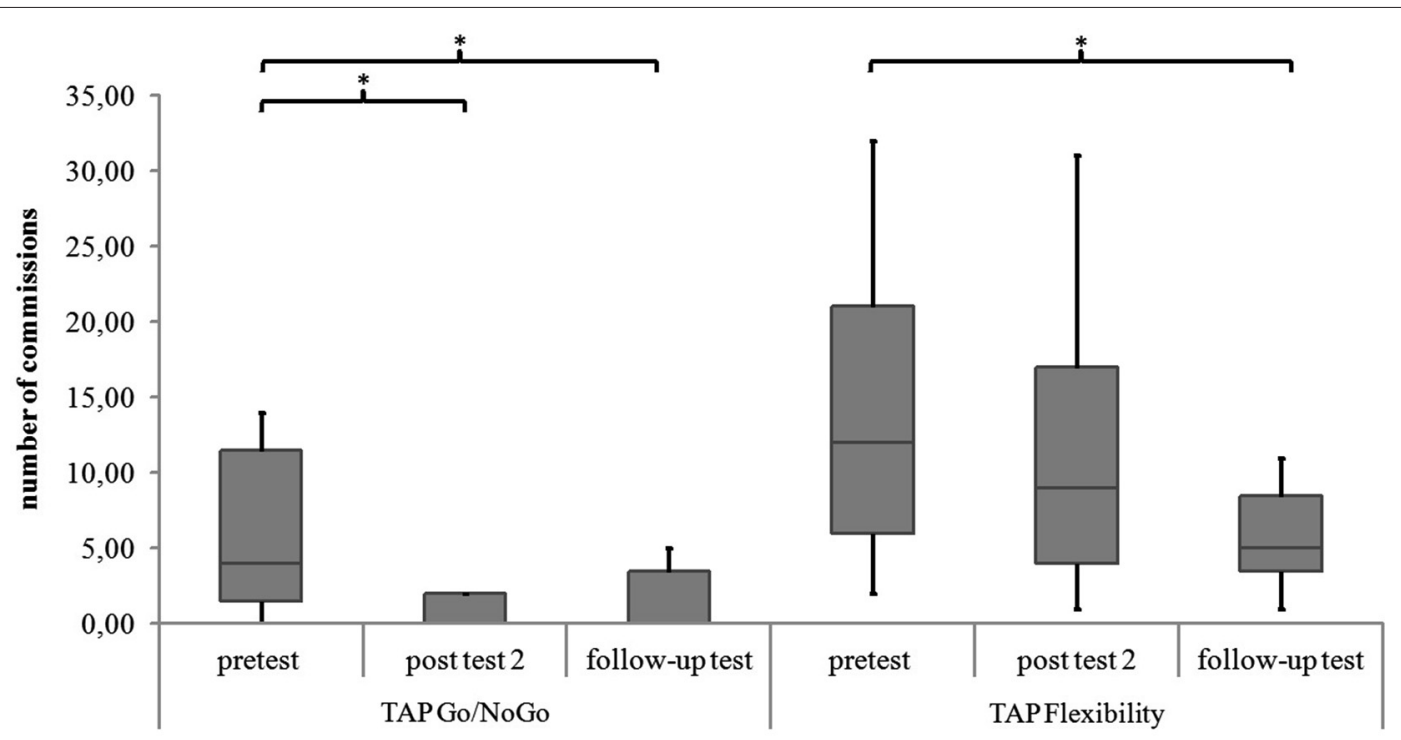

FIGURE 7 | Commissions in the TAP subtests Go/NoGo and Flexibility for all measurement points. Middle line of boxes = median, box = interquartile range, error bars $=$ minimum respectively maximum, ${ }^{*}=$ significant.

Table 4 | Medians and interquartile ranges of FBB-ADHS, KID-KINDL and SDQ at pretest with group statistics.

\begin{tabular}{|c|c|c|c|c|c|}
\hline & & $\begin{array}{c}\text { NIRS-group } \\
n=9\end{array}$ & $\begin{array}{c}\text { EEG-group } \\
n=9\end{array}$ & $\begin{array}{c}\text { EMG-group } \\
n=9\end{array}$ & Kruskal-Wallis \\
\hline $\begin{array}{l}\text { FBB-ADHS } \\
\text { parents total score }\end{array}$ & $\begin{array}{l}\text { Mdn } \\
\text { IQR }\end{array}$ & $\begin{array}{l}1.65 \\
1.33-2.15\end{array}$ & $\begin{array}{l}2.00 \\
1.75-2.23\end{array}$ & $\begin{array}{l}1.75 \\
1.60-1.90\end{array}$ & $\begin{aligned} H(2) & =2.66 \\
p & =0.264\end{aligned}$ \\
\hline total score & $I Q R$ & $0.80-2.15$ & $0.61-1.45$ & $0.56-2.45$ & $p=0.421$ \\
\hline KID-KINDL & Mdn & 4.13 & 2.88 & 3.08 & $H(2)=18.12$ \\
\hline total score & $I Q R$ & $3.75-4.46$ & $2.61-2.96$ & $2.59-3.11$ & $p=0.000$ \\
\hline SDO teachers & Mdn & $13.00(n=7)$ & $17.00(n=8)$ & $23.00(n=8)$ & $H(2)=3.41$ \\
\hline total score & $I Q R$ & $10.00-18.00$ & $13.00-18.50$ & $12.50-28.50$ & $p=0.182$ \\
\hline
\end{tabular}

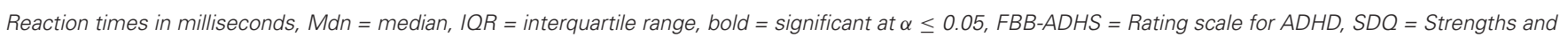
Difficulties Questionnaire, KID-KINDL = Questionnaire for health-related quality of life; if not reported otherwise: $n=9$.

Within-group comparisons to assess the pre-post effect of the twelve sessions separately for each group revealed a significant difference in the parents' rating of the FBB-ADHS only for the NIRS-group $(z=-2.25, p=0.024, r=-0.531$, see Table 5 and Figure 8). A trend for a lower FBB-ADHS score was observed for the EEG-group $(z=-1.90, p=0.058, r=-0.447)$ and the EMGgroup $(z=-1.84, p=0.066, r=-0.434)$.

Comparing the three groups in the differences of parents' ratings of the FBB-ADHS (post test 1 values minus pretest values), there were no significant differences between the groups (NIRS: $M d n=-0.65, I Q R=-1.03--0.11$; EEG: $M d n=-0.60$, $I Q R=-1.06-0.03$; EMG: $M d n=-0.20, I Q R=-0.38-0.04$; $H(2)=2.72, p=0.256)$.

\section{DISCUSSION}

In this pilot study NIRS-neurofeedback as a new method of neurofeedback training for children with ADHD was investigated.
Hemodynamic brain activity in the dorsolateral prefrontal cortex was measured and fed back. Children should learn to gain control over their brain activity in 12 training sessions and 3 weeks of transfer exercises. Primary outcome was the effect on ADHD symptoms rated by parents. Teachers' ratings of symptoms as well as ratings of associated behavioral symptoms by parents and teachers, self-rated quality of life and performance in a computer based attention task were assessed. In addition, a comparison with two other feedback methods (EEG, EMG) was carried out.

\section{NIRS -NEUROFEEDBACK-EFFECTS AND FEASIBILITY}

As primary outcome, parents' ratings of ADHD symptoms in the NIRS-group were significantly reduced 4 weeks and 6 months after the training. Teachers' ratings of ADHD symptoms showed a significant reduction 4 weeks after the end of treatment. Attention and impulsivity in the computer based attention test TAP improved significantly (Go/NoGo: speed, 
Table 5 | Parents' ratings of the FBB-ADHS at pretest and post test 1 for the three groups with test statistics.

\begin{tabular}{|c|c|c|c|c|}
\hline & & $\begin{array}{l}\text { FBB-ADHS total } \\
\text { score pretest }\end{array}$ & $\begin{array}{l}\text { FBB-ADHS total } \\
\text { score post test } 1\end{array}$ & $\begin{array}{l}\text { Wilcoxon signed } \\
\text { rank Test }\end{array}$ \\
\hline \multirow[t]{2}{*}{ NIRS-group } & Mdn & 1.65 & 1.25 & $z=-2.25$ \\
\hline & $I Q R$ & $1.33-2.15$ & $0.83-1.44$ & $\begin{aligned} \boldsymbol{p} & =\mathbf{0 . 0 2 4} \\
r & =-0.531\end{aligned}$ \\
\hline \multirow[t]{2}{*}{ EEG-group } & $M d n$ & 2.00 & 1.40 & $z=-1.90$ \\
\hline & $I Q R$ & $1.75-2.23$ & $1.18-1.53$ & $\begin{array}{l}p=0.058 \\
r=-0.447\end{array}$ \\
\hline \multirow[t]{2}{*}{ EMG-group } & Mdn & 1.75 & 1.60 & $z=-1.84$ \\
\hline & $I Q R$ & $1.60-1.90$ & $1.20-1.90$ & $\begin{array}{l}p=0.066 \\
r=-0.434\end{array}$ \\
\hline
\end{tabular}

$M d n=$ median, $I Q R=$ interquartile range, $r=$ effect size, bold $=$ significant $a t$ $\alpha \leq 0.05, F B B-A D H S=$ Rating scale for $A D H D$.

variability, commissions; Flexibility: variability, commissions). According to these results, NIRS-neurofeedback might be as effective in reducing the main symptoms of $\mathrm{ADHD}$, as it was shown before in randomized controlled studies for EEGneurofeedback (e.g., Gevensleben et al., 2009; Meisel et al., 2013).

The effect size for the parents' ratings of ADHD symptoms in the NIRS-group was high for pre-post comparison $(r=-0.587)$. This is comparable to effect-sizes of EEGneurofeedback as reported in the meta-analysis of Arns et al. (2009). Here, high effect sizes for inattention and impulsivity and medium effect sizes for hyperactivity in pre-post designs of EEG-neurofeedback-studies were observed. With larger sample sizes in NIRS-neurofeedback, a differentiated analysis of effects on symptom groups (inattention, impulsivity, hyperactivity) could be conducted, allowing detailed comparisons with effect sizes of EEG-neurofeedback.

The general question of feasibility of NIRS-neurofeedback for children with ADHD can be answered by taking into account different variables. On the one hand, the technical implementation was possible; on the other hand, children and parents accepted the procedure. All nine children took part in all twelve sessions. At the beginning of each training session, motivation was rated on a 4 -point smiley scale ( $1=$ totally motivated, 2 = quite motivated, $3=$ not much motivated, $4=$ not motivated at all). The mean motivation over all sessions and children was high $(M=1.51$; $s d=0.89)$. Parents rated their satisfaction with the training on a six-item scale 4 weeks and 6 months after the training. They were asked to rate satisfaction with the training, satisfaction with the trainer, empathy of the trainer, trust in the training, trust in the competence of the trainer and recommendation of the training on a 7 -point scale (endpoints: $0=$ not at all, 7 totally). The mean of parent satisfaction 4 weeks and 6 months after training was high (post test 2: $M=5.48, s d=0.58$, follow-up test: $M=5.57$, $s d=0.57$ ). Additionally, parents were asked for adverse side effects in relation to measurement and training at all measurement points. No serious adverse events were documented. Two children reported to have had transient headaches directly after some of the training sessions, possibly caused by the fixation of the probe set. In conclusion, NIRS-neurofeedback seems to be a feasible and accepted intervention for children with ADHD.

\section{COMPARISON WITH EEG-NEUROFEEDBACK AND EMG-FEEDBACK AND FUTURE DIRECTIONS}

The NIRS-group showed a significant reduction of ADHD symptoms in parents' ratings after twelve training sessions. A trend towards decreased ADHD symptoms was observed for

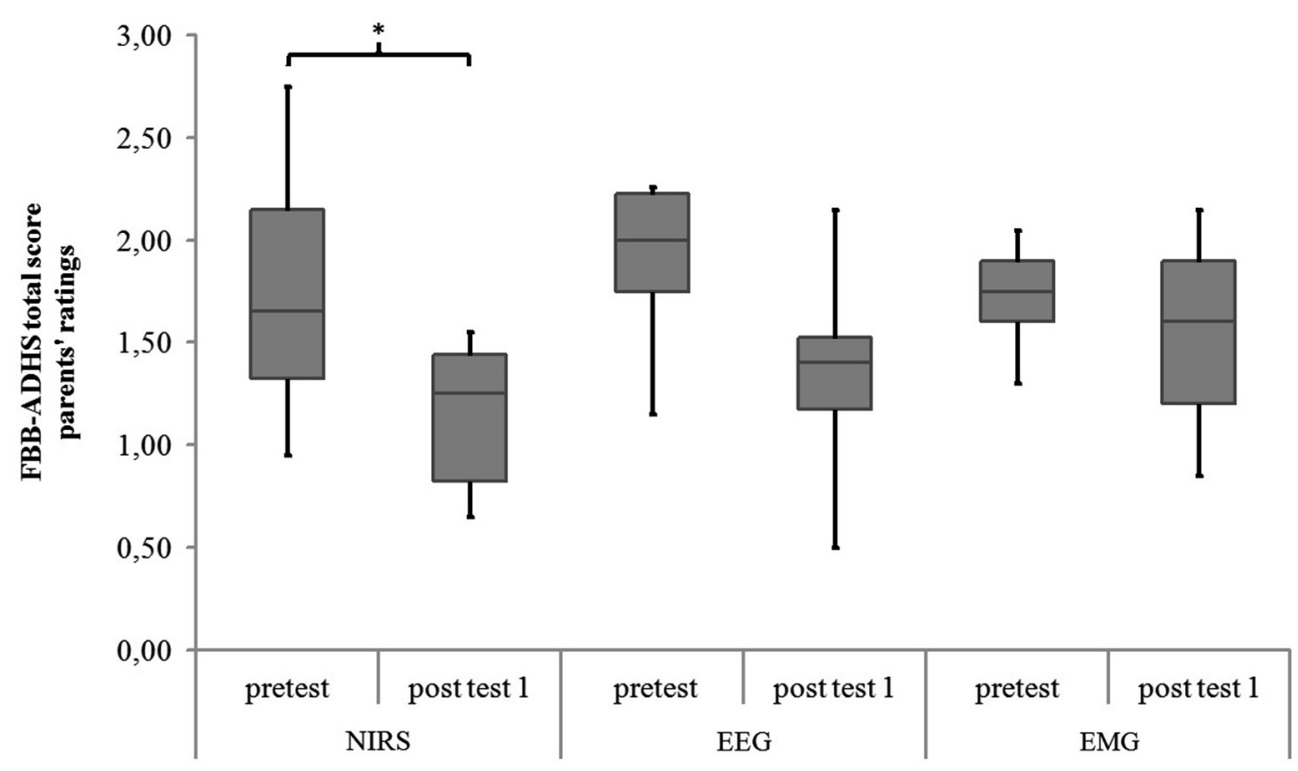

FIGURE 8 | FBB-ADHS total score of parents' ratings for NIRS-, EEG- and EMG-group at pretest and post test 1 . Middle line of boxes = median,

box = interquartile range, error bars = minimum respectively maximum, * = significant. 
the EEG- and the EMG-group. In the between group comparison there were no significant differences in symptom reduction. Despite the matching, the three groups differed significantly in some of the initial values of clinical impairment (quality of life and associated behavioral problems).

NIRS-neurofeedback was effective in the reduction of the main symptoms of ADHD and possibly more time-effective in comparison to EEG-neurofeedback. However, this interpretation has to be confirmed, due to the fact that differences in improvement after the 12 sessions did not reach significance, and that the initial values in quality of life and associated behavioral symptoms of the groups differed. Moreover, a completed intervention was compared with two uncompleted interventions, based on the assumption of a more rapid improvement with NIRS neurofeedback, and the sample sizes were small. For future studies, sample sizes have to be enlarged and a randomized controlled design is mandatory. NIRS-neurofeedback could enlarge the treatment options for $\mathrm{ADHD}$, with the possible advantage of being a shorter intervention in comparison to EEG-neurofeedback. The analysis of NIRS-data throughout the training will hopefully allow conclusions as regards to the learning of self-regulation and number of sessions needed. Birbaumer et al. (2013) assume that faster learning of self-regulation of blood oxygenation in comparison to neuroelectricity is associated with the sensoric input processed for the vascular system allowing a faster development of an adequate response. Future studies should analyze the differences in the protocols and learning curves of NIRS- and EEG-neurofeedback to gain more insights into the underlying mechanisms of self-regulation. As regards to the different velocity of the feedback signals one might speculate that a slower signal facilitates learning. In the absence of any study investigating this issue it should be noted for future research.

As a limitation it has to be taken into account, that medication could have a distorting effect on the results: seven of nine children in each group received a medication with methylphenidate during the training. The effects of medication were not assessable in this study. It might be possible, that symptom reduction only occurs in less impaired children or because medication allows a better training. Larger sample sizes, subgroups with medicated and unmedicated children are necessary to control for effects of medication. As an example, results of the multicenter study (comparison of EEG- and EMG-feedback), show that effects of neurofeedback were independent of medication (Holtmann et al., 2014c) and the relationship between symptom severity and outcome is inverse.

Whether NIRS-neurofeedback can be implemented as a stand-alone or part of a multimodal treatment of ADHD will only be answered after studies with a corresponding design. A combination of different interventions according to individual forming of problems is another field of future research in the treatment of ADHD. A multi-center stepped care study dealing with severity-adapted combined interventions including SCP-neurofeedback will be conducted in Germany from February 2015 (ESCAlife: Evidence-based, Stepped Care of ADHS along the life-span $)^{1}$. Results could

${ }^{1}$ Project description: http://akip.uk-koeln.de/forschung-publikation/forsch ungsprojekte/fg_esca_06_2014_weg.pdf [14.09.2014] give a hint on additional effects of neurofeedback and medication.

NIRS-neurofeedback is a promising intervention for children with ADHD and can enlarge the range of options for a treatment of ADHD. Future studies should focus on randomized controlled designs. Especially the comparison with EEG-neurofeedback, and with its final rather than its intermediate outcome, is necessary to further support the assumption that NIRS-neurofeedback needs fewer sessions for comparable symptom reduction. It would also be important to clarify whether longer NIRS-neurofeedback training (i.e., with more than 12 sessions) yields further clinical improvement. For further development of NIRS-neurofeedback the identification of other possible feedback regions based on the growing number of NIRS-studies with children with ADHD is required. The prefrontal cortex plays a central role in ADHD. However, involving a greater database and identifying target regions according to symptomatology could lead to an evidencebased adaption of feedback protocols for individualized treatment of ADHD.

\section{ACKNOWLEDGMENTS}

We strongly thank the children with ADHD, their parents and teachers for participating in this study. Additionally, we thank Ramona Taeglich, Judith Kittel and Raphaela Kuemmerle for their assistance and the involved staff of IZKS Mainz for providing data from the multicentric neurofeedback study. This work is based on the PhD dissertation of Anna-Maria Marx (Neurofeedback mittels Nah-Infrarot-Spektroskopie als Behandlungsmöglichkeit für Kinder mit einer Aufmerksamkeitsdefizit/Hyperaktivitätsstörung, University of Tuebingen, 2014). It was supported by the Bernstein Computational Neuroscience Program of the German Federal Ministry of Education and Research (Grant number: 01GQ0831). The multicenter study which provided the data of the SCPand EMG-feedback groups was supported by the German Research Foundation (Deutsche Forschungsgemeinschaft [DFG] HO 2503/4-1, BI 195/69-1). We acknowledge support by the Deutsche Forschungsgemeinschaft and the Open Access Publishing Fund of the University of Tuebingen.

\section{REFERENCES}

Achenbach, T. M. (1991). Manual for the Child Behavior Checklist/4-18 and 1991 Profile. Burlington, VT: University of Vermont, Department of Psychiatry.

American Psychiatric Association. (2000). Diagnostic and Statistical Manual of Mental Disorders. Washington, DC: Author.

Arbeitsgruppe Deutsche Child Behavior Checklist. (1998). Elternfragebogen über das Verhalten von Kindern und Jugendlichen; deutsche Bearbeitung der Child Behavior Checklist (CBCL/4-18). Einführung und Anleitung zur Handauswertung, 2. Auflage mit deutschen Normen. Köln: Arbeitsgruppe Kinder-, Jugendund Familiendiagnostik.

Arnold, D. S., O’leary, S. G., Wolff, L. S., and Acker, M. M. (1993). The parenting scale: a measure of dysfunctional parenting in discipline situations. Psychol. Assess. 5, 137-144. doi: 10.1037//1040-3590.5.2.137

Arns, M., de Ridder, S., Strehl, U., Breteler, M., and Coenen, A. (2009). Efficacy of neurofeedback treatment in ADHD: the effects on inattention, impulsivity and hyperactivity: a meta-analysis. Clin. EEG Neurosci. 40, 180-189. doi: 10. 1177/155005940904000311

Arns, M., Heinrich, H., and Strehl, U. (2013). Evaluation of neurofeedback in ADHD: the long and winding road. Biol. Psychol. 95, 108-115. doi: 10.1016/j. biopsycho.2013.11.013

Ayaz, H., Shewokis, P., Bunce, S., Schultheis, M., and Onaral, B. (2009). "Assessment of cognitive neural correlates for a functional near infrared-based brain 
computer interface system," in Foundations of Augmented Cognition. Neuroergonomics and Operational Neuroscience, eds D. D. Schmorrow et al. (Berlin Heidelberg: Springer Verlag), 699-708.

Barkley, R. A. (1997). Behavioral inhibition, sustained attention and executive functions: constructing a unifying theory of ADHD. Psychol. Bull. 121, 65-94. doi: 10.1037//0033-2909.121.1.65

Barry, R. J., Clarke, A. R., and Johnstone, S. J. (2003a). A review of electrophysiology in attention-deficit/hyperactivity disorder: I. Qualitative and quantitative electroencephalography. Clin. Neurophysiol. 114, 171-183. doi: 10.1016/s13882457(02)00362-0

Barry, R. J., Johnstone, S. J., and Clarke, A. R. (2003b). A review of electrophysiology in attention-deficit/hyperactivity disorder: II. Event-related potentials. Clin. Neurophysiol. 114, 184-198. doi: 10.1016/s1388-2457(02)00363-2

Birbaumer, N., Ruiz, S., and Sitaram, R. (2013). Learned regulation of brain metabolism. Trends Cogn. Sci. 17, 295-302. doi: 10.1016/j.tics.2013.04.009

Brennan, A. R., and Arnsten, A. F. (2008). Neuronal mechanisms underlying attention deficit hyperactivity disorder: the influence of arousal on prefrontal cortical function. Ann. N Y Acad. Sci. 1129, 236-245. doi: 10.1196/annals. 1417.007

Bulheller, S., and Häcker, H. O. (2006). Coloured Progressive Matrices (CPM). Deutsche Bearbeitung und Normierung nach J. C. Raven. Frankfurt: Harcourt Test Services.

Caria, A., Sitaram, R., Veit, R., Begliomini, C., and Birbaumer, N. (2010). Volitional control of anterior insula activity modulates the response to aversive stimuli. A real-time functional magnetic resonance imaging study. Biol. Psychiatry 68, 425-432. doi: 10.1016/j.biopsych.2010.04.020

Caria, A., Veit, R., Sitaram, R., Lotze, M., Welskopf, N., Grodd, W., et al. (2007). Regulation of anterior insular cortex activity using real-time fMRI. Neuroimage 35, 1238-1246. doi: 10.1016/j.neuroimage.2007.01.018

Delmo, C., Weiffenbach, O., Gabriel, M., and Poustka, F. (2000). 3. Auflage der Deutschen Forschungsversion des K-SADS-PL, Erweitert um ICD-10-Diagnostik. Bern: Huber.

Dickstein, S. G., Bannon, K., Castellanos, F. X., and Milham, M. P. (2006). The neural correlates of attention deficit hyperactivity disorder: an ALE metaanalysis. J. Child Psychol. Psychiatry 47, 1051-1062. doi: 10.1111/j.1469-7610. 2006.01671.x

Döpfner, M., Görtz-Dorten, A., and Lehmkuhl, G. (2008). Diagnostik-System für psychische Störungen im Kindes- und Jugendalter nach ICD-10 und DSM-IV (DISYPS-II). Bern: Huber.

Ehlis, A. C., Bähne, C. G., Jacob, C. P., Herrmann, M. J., and Fallgatter, A. J. (2008). Reduced lateral prefrontal activation in adult patients with attentiondeficit/hyperactivity disorder (ADHD) during a working memory task: a functional near-infrared spectroscopy (fNIRS) study. J. Psychiatr Res. 42, 10601067. doi: 10.1016/j.jpsychires.2007.11.011

Ehlis, A. C., Schneider, S., Dresler, T., and Fallgatter, A. J. (2014). Application of functional near-infrared spectroscopy in psychiatry. Neuroimage 85, 478-488. doi: 10.1016/j.neuroimage.2013.03.067

Fallgatter, A. J., and Strik, W. K. (1997). Right frontal activation during the continuous performance test assessed with near-infrared spectroscopy in healthy subjects. Neurosci. Lett. 223, 89-92. doi: 10.1016/s0304-3940(97) $13416-4$

Gevensleben, H., Holl, B., Albrecht, B., Vogel, C., Schlamp, D., Kratz, O., et al. (2009). Is neurofeedback an efficacious treatment for ADHD? A randomised controlled clinical trial. J. Child Psychol. Psychiatry 50, 780-789. doi: 10.1111/j. 1469-7610.2008.02033.x

Goodman, R. (1997). The strengths and difficulties questionnaire: a research note. J. Child Psychol. Psychiatry 38, 581-586. doi: 10.1111/j.1469-7610.1997. tb01545.x

Guy, W. (1976). ECDEU Assessment Manual for Psychopharmacology. Rockville, MD, U.S. Department of Health, Education and Welfare. Available online at: http://miksa.ils.unc.edu/unc-hit/media/CGI.pdf. Accessed on May 13, 2014.

Holtmann, M., Pniewski, B., Wachtlin, D., Wörz, S., and Strehl, U. (2014a). Neurofeedback in children with attention-deficit/hyperactivity disorder (ADHD)—a controlled multicenter study of a non-pharmacological treatment approach. BMC Pediatr. 14:202. doi: 10.1186/1471-2431-14-202

Holtmann, M., Sonuga-Barke, E., Cortese, S., and Brandeis, D. (2014b). Neurofeedback for ADHD: a review of current evidence. Child Adolesc. Psychiatr. Clin. N. Am. 23, 789-806. doi: 10.1016/j.chc.2014.05.006
Holtmann, M., Wörz, S., Brandeis, D., Banaschewski, T., Baumeister, S., Bogen, T., et al. (2014c). "Neurofeedback in children with ADHD—first results of a controlled multicenter study," in Poster 3rd Eunethydis International Conference on ADHD.21st - 24th May 2014. Scientific programme (Istanbul, Turkey), 278 (abstract).

Inoue, Y., Sakihara, K., Gunji, A., Ozawa, H., Kimiya, S., Shinoda, H., et al. (2012). Reduced prefrontal hemodynamic response in children with ADHD during the Go/NoGo task: a NIRS study. Neuroreport 23, 55-60. doi: 10.1097/wnr. 0b013e32834e664c

Jourdan Moser, S., Cutini, S., Weber, P., and Schroeter, M. L. (2009). Right prefrontal brain activation due to stroop interference is altered in attention-deficit hyperactivity disorder-a functional near-infrared spectroscopy study. Psychiatry Res. 173, 190-195. doi: 10.1016/j.pscychresns.2008. 10.003

Kaufman, J., Birmaher, B., Brent, D., Rao, U. M. A., Flynn, C., Moreci, P., et al. (1997). Schedule for affective disorders and schizophrenia for school-age children-present and lifetime version ( $\mathrm{k}$-sads-pl): initial reliability and validity data. J. Am. Acad. Child Adolesc. Psychiatry 36, 980-988. doi: 10.1097/00004583199707000-00021

Kaufman, J., and Schweder, A. E. (2003). "The schedule for affective disorders and schizophrenia for school age children: present and lifetime version (K-SADS-PL)," in The Comprehensive Handbook of Psychological Assessment (CHOPA), Volume 2: Personality Assessment, eds M. Hersen, D. M. Segal and M. Hilsenroth (New-York: John Wiley and Sons), 247-255.

Martinussen, R., Hayden, J., Hogg-Johnson, S., and Tannock, R. (2005). A meta-analysis of working memory impairments in children with attentiondeficit/hyperactivity disorder. J. Am. Acad. Child Adolesc. Psychiatry 44, 377-384. doi: 10.1097/01.chi.0000153228.72591.73

Marx, A.-M. (2014). Neurofeedback mittels Nah-Infrarot-Spektroskopie als Behandlungsmöglichkeit für Kinder mit einer Aufmerksamkeitsdefizit/Hyperaktivitätsstörung. Muenchen: Verlag Dr. Hut.

Meisel, V., Servera, M., Garcia-Banda, G., Cardo, E., and Moreno, I. (2013). Neurofeedback and standard pharmacological intervention in ADHD: a randomized controlled trial with six-month follow-up. Biol. Psychol. 94, 12-21. doi: 10. 1016/j.biopsycho.2013.04.015

Miller, Y. (2001). Erziehung von Kindern im Kindergartenalter: Erziehungsverhalten und Kompetenzüberzeugungen von Eltern und der Zusammenhang zu kindlichen Verhaltensstörungen. Dissertation, TU Braunschweig.

Negoro, H., Sawada, M., Iida, J., Ota, T., Tanaka, S., and Kishimoto, T. (2010). Prefrontal dysfunction in attention-deficit/hyperactivity disorder as measured by near-infrared spectroscopy. Child Psychiatry Hum. Dev. 41, 193-203. doi: 10. 1007/s10578-009-0160-y

Obrig, H., Wenzel, R., Kohl, M., Horst, S., Wobst, P., Steinbrink, J., et al. (2000). Near-infrared spectroscopy: does it function in functional activation studies of the adult brain? Int. J. Psychophysiol. 35, 125-142. doi: 10.1016/s01678760(99)00048-3

Paloyelis, Y., Mehta, M. A., Kuntsi, J., and Asherson, P. (2007). Functional MRI in ADHD: a systematic literature review. Expert Rev. Neurother. 7, 1337-1356. doi: 10.1586/14737175.7.10.1337

Raven, J. C., Raven, J., and Court, J. H. (1998). Manual for Raven's Progressive Matrices and Vocabulary Scales. San Antonio, TX: Pearson.

Ravens-Sieberer, U. (2003). "Der KINDL@-Fragebogen zur Erfassung der gesundheitsbezogenen Lebensqualität bei Kindern und Jugendlichen-Revidierte Form," in Diagnostische Verfahren zu Lebensqualität und Wohlbefinden, eds J. Schumacher, A. Klaiberg and E. Brähler (Göttingen: Hogrefe), 184-188.

Rothenberger, A., and Woerner, W. (2004). Strengths and Difficulties Questionnaire (SDQ)-evaluations and applications. Eur. Child Adoles. Psychiatry 13, II1II2. doi: 10.1007/s00787-004-2001-7

Strangman, G., Culver, J. P., Thompson, J. H., and Boas, D. A. (2002). A quantitative comparison of simultaneous BOLD fMRI and NIRS recordings during functional brain activation. Neuroimage 17, 719-731. doi: 10.1006/nimg.2002. 1227

Tsuzuki, D., Jurcak, V., Singh, A. K., Okamoto, M., Watanabe, E., and Dan, I. (2007). Virtual spatial registration of stand-alone fNIRS data to MNI space. Neuroimage 34, 1506-1518. doi: 10.1016/j.neuroimage.2006. 10.043 
Tzourio-Mazoyer, N., Landeau, B., Papathanassiou, D., Crivello, F., Etard, O., Delcroix, N., et al. (2002). Automated anatomical labeling of activations in SPM using a macroscopic anatomical parcellation of the MNI MRI single-subject brain. Neuroimage 15, 273-289. doi: 10.1006/nimg.2001. 0978

Weber, P., Lütschg, J., and Fahnenstich, H. (2005). Cerebral hemodynamic changes in response to an executive function task in children with attention-deficit hyperactivity disorder measured by near-infrared spectroscopy. J. Dev. Behav. Pediatr. 26, 105-111. doi: 10.1097/00004703-20050400000005

Weiskopf, N., Scharnowski, F., Veit, R., Goebel, R., Birbaumer, N., and Mathiak, K. (2004). Self-regulation of local brain activity using real-time functional magnetic resonance imaging (fMRI). J. Physiol. Paris 98, 357-373. doi: 10.1016/j. jphysparis.2005.09.019

Weiskopf, N., Veit, R., Erb, M., Mathiak, K., Grodd, W., Goebel, R., et al. (2003). Physiological self-regulation of regional brain activity using real-time functional magnetic resonance imaging (fMRI): methodology and exemplary data. Neuroimage 19, 577-586. doi: 10.1016/s1053-8119(03)00145-9

Willcutt, E. G., Doyle, A. E., Nigg, J. T., Faraone, S. V., and Pennington, B. F. (2005). Validity of the executive function theory of attention-deficit/hyperactivity disorder: a meta-analytic review. Biol. Psychiatry 57, 1336-1346. doi: 10.1016/j. biopsych.2005.02.006

Xiao, T., Xiao, Z., Ke, X., Hong, S., Yang, H., Su, Y., et al. (2012). Response inhibition impairment in high functioning autism and attention deficit hyperactivity disorder: evidence from near-infrared spectroscopy data. PLoS One 7:e46569. doi: 10.1371/journal.pone.0046569

Yamamoto, T., and Kato, T. (2002). Paradoxical correlation between signal in functional magnetic response imaging and deoxygenated haemoglobin content in capillaries: a new theoretical explanation. Phys. Med. Biol. 47, 1121-1141. doi: 10.1088/0031-9155/47/7/309

Yasumura, A., Inagaki, M., and Hiraki, K. (2014). Relationship between neural activity and executive function: an NIRS study. ISRN Neurosci. 2014:734952. doi: $10.1155 / 2014 / 734952$

Zimmermann, P., and Fimm, B. (2009). TAP-Testbatterie zur Aufmerksamkeitsprüfung (Testbattery for Attentional Performance). 2.2 Edn. Herzogenrath, Germany: Psytest.
Conflict of Interest Statement: Anna-Maria Marx, Adrian Furdea, Yvonne Fuchsenberger, Holger Gevensleben, Daniel Brandeis, Ann-Christine Ehlis and Andreas J. Fallgatter declare no commercial or financial relationships that could be construed as a potential conflict of interest. Ute Strehl was paid for public speaking by Novartis, Medice, Neuroconn, the German Society for Biofeedback and Akademie König und Müller. Martin Holtmann served in an advisory or consultancy role for Lilly, Shire and Bristol-Myers Squibb, and received conference attendance support or was paid for public speaking by Bristol-Myers Squibb, Janssen-Cilag, Lilly, Medice, Neuroconn, Novartis and Shire. Christine M. Freitag received one time speaker's fees by Ely Lilly and Shire over the last 3 years. Tobias Banaschewski served in an advisory or consultancy role for Hexal Pharma, Lilly, Medice, Novartis, Otsuka, Oxford outcomes, PCM scientific, Shire and Viforpharma. He received conference attendance support and conference support or received speaker's fee by Lilly, Medice, Novartis and Shire. He is/has been involved in clinical trials conducted by Lilly, Shire and Viforpharma. The present work is unrelated to the above grants and relationships. Prof. Rothenberger is member of an advisory board and speakers' bureau of Lilly, Shire, Medice and Novartis. He got research and travel support and an educational grant from Shire and research support from the German Research Society. Where applicable, the above mentioned authors declare that the present work is unrelated to the above mentioned grants and relationships.

Received: 30 September 2014; accepted: 11 December 2014; published online: 07 January 2015.

Citation: Marx A-M, Ehlis A-C, Furdea A, Holtmann M, Banaschewski T, Brandeis $D$, Rothenberger A, Gevensleben H, Freitag CM, Fuchsenberger Y, Fallgatter AJ and Strehl U (2015) Near-infrared spectroscopy (NIRS) neurofeedback as a treatment for children with attention deficit hyperactivity disorder (ADHD)—a pilot study. Front. Hum. Neurosci. 8:1038. doi: 10.3389/fnhum.2014.01038

This article was submitted to the journal Frontiers in Human Neuroscience.

Copyright (c) 2015 Marx, Ehlis, Furdea, Holtmann, Banaschewski, Brandeis, Rothenberger, Gevensleben, Freitag, Fuchsenberger, Fallgatter and Strehl. This is an openaccess article distributed under the terms of the Creative Commons Attribution License $(C C B Y)$. The use, distribution and reproduction in other forums is permitted, provided the original author(s) or licensor are credited and that the original publication in this journal is cited, in accordance with accepted academic practice. No use, distribution or reproduction is permitted which does not comply with these terms. 